\title{
HOMEOPATHY: DO NOT CONDEMN WHAT WE DO NOT UNDERSTAND
}

(ref. Almeida RMVR. A Critical review of the possible benefits associated with homeopathic medicine. Rev Hosp Clin Fac Med S.Paulo 2003; 58(6):324-331)

Almeida's 'critical' review of homeopathy ${ }^{1}$ is not based on systematic review of the evidence and is strongly biased against homeopathy.

There have been three systematic reviews/meta-analyses of 'general' scope (ie including all clinical trials of homeopathy), published in peer-reviewed journals. All have yielded positive conclusions ${ }^{2-4}$. Almeida conceals these conclusions by highly selective quotation, for instance omitting the headline conclusion of the meta-analysis published in The Lancet 'The results of our meta-analysis are not compatible with the hypothesis that the clinical effects of homoeopathy are completely due to placebo'. But he quotes (inaccurately) the secondary conclusion 'However, we found insufficient evidence from these studies that homoeopathy is clearly efficacious for any single clinical condition'. He states that the effect of publication bias is difficult to estimate, while omitting to mention that a funnel plot estimate, included in the analysis, showed that 923 unpublished studies are required (compared to the 89 included in the meta-analysis) to make the conclusions insignificant. $^{2}$

Almeida claims to cite systematic reviews and meta-analyses of homeo- pathic treatment of a number of conditions, including allergic rhinitis, post-operative ileus and arthritis, with negative results. In fact the publications he cites are single clinical trials; systematic reviews and meta-analyses in these areas are positive $e^{5-8}$. Almeida mocks the possibility of structural effects in water, ignoring recent evidence ${ }^{9}$.

We could show many other biases, inconsistencies and omissions, but there is little point. This is not a critical review but an exercise in 'Damnant quod non intelligunt' - condemning what he does not understand. Homeopathy is challenging: the claims made for the actions of very high dilutions cannot be explained in terms of classical pharmacology. The evidence is far from conclusive or perfect, but there is a substantial and growing body of positive evidence which demands to be taken seriously.

As a therapeutic method, homeopathy is remarkably durable, widespread and popular. According to the European Commission 'Three out of four Europeans know about homeopathy, and of these $29 \%$ use it for their healthcare' ${ }^{10}$; in the USA sales of homeopathic medicines rose by $500 \%$ in a 7 year period in the 1990 's ${ }^{11}$. It is practised by tens of thousands of doctors worldwide, and in Brazil is a medical speciality officially recognized by all main medical organizations (Conselho Federal de Medicina, Associação Médica Brasileira e Comissão Nacional de Residência Médica).

Denying the evidence, as Almeida does, is futile. What is needed is creative and collaborative scientific endeavour to meet the scientific and clinical challenges raised by homeopathy.

Peter Fisher

Clinical Director

Royal London Homoeopathic Hospital

University College London Hospitals Great Ormond Street, London WCIN $3 H R-U K$

Peter.fisher@uclh.org

Flávio Dantas

Professor of Homeopathy, Federal

University of Uberlândia

Visiting Professor, Federal University

of São Paulo,

Rua Pedro de Toledo 920 São Paulo-

SP, 04039-020, Brazil fdantas@climed.epm.br 


\section{REFERENCES}

1. Almeida RMVR. A Critical review of the possible benefits associated with homeopathic medicine. Rev Hosp Clin Fac Med S.Paulo 2003; 58(6):324-331

2. Kleijnen J, Knipschild P, ter Riet G. Clinical trials of homeopathy, Brit Med J 1991; 302: 316-323.

3. Linde K, Clausius N, Ramirez G, Melchart D, Eitel F, Hedges L, et al. Are the clinical effects of homeopathy placebo effects? A meta-analysis of placebo controlled trials. Lancet 1997; 350: 834-43.

4. Cucherat M, Haugh MC, Gooch M, Boissel JP. Evidence of clinical efficacy of homeopathy - A meta-analysis of clinical trials. Eur J Clin Pharmacol 56, 2000:27-33

5. Reilly DT, Taylor MA, Beattie NGM, Campbell JH. Is evidence for homoeopathy reproducible? Lancet 344, 1994: 1601-1606.

6. Barnes J, Resch KL, Ernst E. Homeopathy for Postoperative Ileus? - A Meta-Analysis. J Clin Gastroenterol 25(4), 1997: 628-633
7. Long L, Ernst E. Homeopathic remedies for the treatment of osteoarthritis -A systematic review. Brit Hom J 90(1), 2001: $37-43$

8. Jonas WB, Linde K, Ramirez G. Homeopathy and rheumatic disease -Complementary and Alternative Therapies for Rheumatic Diseases II. Rheumatic Disease Clin North Am 26(1), 2000: 117-123

9. Rey L. Thermoluminescence of ultra-high dilutions of lithium chloride and sodium chloride, Physica, A 323 : 67-74, 2003

10. Commission report to the European Parliament on application of directives 92/73 and 92/74 Com (97) 362 p1

11. Eisenberg D, Davis R, Ettner S, Appel S, Wilkey S, Rompay M, et al. Trends in alternative medicine use in the United States, 1990-1997. JAMA 1998;280:1569-1575. 